\title{
1 Social capital in sociological research: conceptual rigour and empirical application Yaojun $\mathrm{Li}$
}

\section{INTRODUCTION}

In the past two decades, the concept of social capital has captured the imagination and attention of social science researchers and policy-makers more than many other sociological constructs, with the number of publications in this area increasing exponentially (Halpern, 2005; Field, 2008). The concept is used not only in sociology and political sciences, but also in education, economics, business and management, epidemiology, community cohesion, immigrant integration, poverty and crime reduction, race and ethnicity relations, health and life satisfaction research and, indeed, in almost all social science disciplines. This is hardly surprising, as social capital is fundamentally concerned with resources embedded in social relations and as social science research in the various disciplines seeks to discover the dynamics between agency and structure, that is, how individuals and communities resort to, or are constrained by, resources in their relations as they try to solve personal and collective problems.

As Portes (1998) observes, the concept of social capital is probably the best example of a sociological construct being 'exported' to other disciplines. While the continued interest in and the application of social capital as a tool in social science research is evidence of its vitality, there is also a risk that it is becoming over-general (Fine, 2002). Within sociology and political sciences, scholars in this field of research tend to work in one of the two traditions, instrumental or civic, as exemplified by Lin and Putnam (Lin, 2001, 2008; Putnam, 2000, 2002). Even though both Lin and Putnam acknowledge that social capital can be both private and public goods (as well as private and public 'bads', the dark side), there is a clear tendency for researchers to focus on either the individual or the collective domain in the application. The interrelationships between the different domains of social capital, and their determinants and consequences, call for more systematic attention.

In this volume, we bring together researchers in the USA, Canada, Australia, the UK, Spain, the Netherlands and China to contribute to the ongoing debate on social capital. We focus on the sociological analysis of the concept, namely, the conceptualization and measurement of the different domains of social networks, the interrelated nature of the domains, the links with cultural and economic capital, the socioeconomic determinants, and the instrumental and the civic (expressive) effects. The authors are all experts in their specialist areas and they use the best possible data available and appropriate methods to address the specific issues at hand. While all the chapters are theoretically guided, the focus is on the empirical application of social capital.

In this chapter, we give a brief account of the conceptual and measurement issues related to the works of four leading theorists on social capital, summarize the main 


\section{Handbook of research methods and applications in social capital}

debate on social involvement in the USA and the UK, and develop a framework of using social capital for sociological analysis. We also provide a brief summary of the findings in the contributing chapters.

\section{CONCEPTUAL AND MEASUREMENT ISSUES OF SOCIAL CAPITAL}

While there are many debates on the nature of social capital and its relationship with various socioeconomic outcomes, ${ }^{1}$ there is a consensus amongst the leading authors that social capital refers to resources residing in social networks. Much has been written on the conceptual journey of social capital (Portes, 1998; Putnam, 2000, 2002; Lin, 2001, 2006, 2008), which will not be repeated here. We focus on the conceptual and measurement issues of social capital as defined by the four leading authors and the implications for sociological analysis: Bourdieu, Coleman, Lin and Putnam.

Bourdieu sees social capital as part of the strategies for social reproduction whereby the advantaged help their children in educational and occupational careers. He emphasizes the accumulation, conservation and transmission of social, cultural and economic capitals which are largely fungible and which mainly serve instrumental purposes (with all three capitals rooted in the economic sphere). He views social capital as 'the aggregate of the actual or potential resources which are linked to possession of a durable network of more or less institutionalized relationships of mutual acquaintance and recognition' (1986: 51). Social capital depends on the size of the social networks as well as the amount and quality of resources (prestige, power and wealth) that are contained in the networks, resources that are directly usable in the short or longer run. Economic and cultural capitals are in people's own possession and can be directly used in pursuit of their goals. Social capital has to be mobilized and in order to gain access to it, families would 'endlessly' invest in sociability (1986: 52) to cultivate and consolidate social relations. Middle-class families would use a combination of social, economic and cultural capitals in helping their children achieve educational and occupational success. Most importantly, they would use their superior resources to give their children a favourable start in education by, say, moving to catchment areas where good quality schools are located or sending them to fee-paying schools or paying for extra tuition. In such processes, economic capital is crucial. Cultural capital, in terms of parental knowledge (gained through higher qualifications in the institutionalized form), books and other learning materials at home (in the objectified form), and a pro-learning environment for the cultivation of 'habitus' including visits to art galleries, museums or stately homes (in the embodied form), is of chief importance. Social capital can also be of great value, as contacts in powerful and influential positions or with expert knowledge can give access to good schools or provide guidance on subject matters in the acquisition of educational credentials.

Social capital is important beyond the school stage. When their children enter the labour market, middle-class families will mobilize their social networks in order to find a good job for them. Middle-class children usually have a higher level of achievement than their working-class peers but there are always exceptions. When their children's educational performance does not have a competitive edge, social capital will come to 
their aid. As the social contacts of the middle class are usually in higher positions, they can provide timely and valuable information on or direct access to desirable jobs, especially when such jobs do not require sophisticated technical know-how but high levels of soft (or personal) skills. Social capital in this regard serves as a back-up measure for middle-class reproduction.

The importance of using social networks for access to privileged social positions is well recognized, even by those who are highly critical of Bourdieu's conceptual and analytical rigour. ${ }^{2}$ For instance, Goldthorpe, a leading scholar on social mobility, states that whilst upward mobility for working-class children depends crucially on educational qualifications, for middle-class children with modest educational attainment, 'other resources may be available to help them maintain their parents' position' (Goldthorpe and Jackson, 2008: 105). The 'other resources' are not specified here but one could fairly safely assume that they refer to social resources, namely, people's 'involvement in social networks, and also possibilities for less structured contacts, which can serve as channels of both information and influence' (Goldthorpe, 1987: 99). The use of social resources for the benefit of middle-class children who do not have high levels of educational qualifications has its structural groundings too, namely, the declining value of hard skills and the enhanced value of soft skills. There has been an expansion of higher education in the Western countries in the last few decades and, as a result, the origin differences between the middle and the working classes have narrowed (Breen et al., 2009) and the signalling value of educational qualifications has decreased. The over-supply of people with educational credentials will affect the recruitment process, thereby enabling employers to 'select employees by reference to whatever attributes they believe most relevant to the productive efficiency of their organisations' (Jackson et al., 2005: 27). There has also been a shift from industrial to post-industrial society in the last few decades in the Western countries and in the developing countries, too, such as China, with a steady increase of employment in the tertiary sector, especially in sales and personal service positions. The combination of these and other factors makes access to advantaged class positions within the service sector such as junior managers in restaurants, hotels and shops increasingly dependent on personal (people-processing) skills where attributes of 'looking good and sounding right' (Warhurst and Nickson, 2001) as frequently associated with middleclass upbringing and socialization have a particular advantage. ${ }^{3}$

How families mobilize social resources to help their children's occupational careers has been under-researched. One important study is conducted by Lin (1982) in which he shows that families use both strong and weak ties (Granovetter, 1973; Lin et al., 1981) to help their children to find first jobs. There is a marked difference in the contacts' status that varies with the status of job-seekers' family origin (measured in terms of Duncan's SEI scores for father's occupation). Respondents from high-status (father's SEI scores over 80) families have their strong ties in much higher positions (with a mean score of 65) than those from low-status families (father's score of 19) whose strong ties have a mean score of 28 only, with a difference of 37 points. Interestingly, weak ties' social positions do not vary much with the status positions of job-seekers' family origins except for those from very high-status families. As more advantaged families tend to have larger circles of contacts, including both weak and strong ties, the findings attest to the differential access to social resources whereby class advantages and disadvantages are reproduced. In Britain, we found two such studies: one on the strong association among father's, 


\section{Handbook of research methods and applications in social capital}

father-in-law's and friends' (called 'spare-time associates' in the data) class positions (Mitchell and Critchley, 1985); and the other on the close links between family origins and children's educational and career trajectories (Devine, 2004). Yet how origin and destination advantages (via mobility trajectories) extend beyond informal social networks to include benefits from engagement in formal associational activities in a web of social advantages and disadvantages calls for more attention (see also Li et al., 2008).

Overall, Bourdieu's account of social capital is rooted in the stratification tradition where social capital, just like economic and cultural capitals, serves mainly as an exclusionary device. People without resources to invest in and to maintain formal and informal social connections remain at the bottom of the social hierarchy. As such, Bourdieu's work on social capital is held in high esteem, as 'the first systematic' and 'the most theoretically refined' contemporary analysis (Portes, 1998: 3). As Lareau and Weininger (2003: 568) point out, social capital is one of Bourdieu's 'signature concepts' which is used in his 'social reproduction theory' for explaining strategies of social exclusion. Yet theoretically inspiring as it is, his definition of social capital, which we saw above, as 'a durable network of more or less institutionalized relationships of mutual acquaintance and recognition', defies easy measurement. It is not clear how it can be fully captured in quantitative, especially large-scale survey, research, which may explain why it is mainly used in qualitative and theoretical discussions.

As Bourdieu's work on social capital was initially published in French, it was largely unknown to the English-speaking world. The first influential sociological account in the English-speaking world was given by Coleman (1988, 1990). Unlike Bourdieu, who views cultural capital as the crucial factor and social capital as serving a complementary role for middle-class children's educational development, Coleman's focus is on the role of 'intergenerational closure' and the way in which shared social norms and social control among parents, children and schools help to account for the educational success of children at church (Catholic) schools in the USA. The norms and control can be regarded as social resources within the well-connected communities. For him, social capital is composed of a variety of 'entities' with two common characteristics: 'They all consist of some aspect of a social structure, and they facilitate certain actions of individuals who are within the structure' (Coleman, 1990: 302). When parents, students and teachers are all in a network, norms can be instilled, mutual support provided, discipline reinforced, school attrition and teenage pregnancy reduced, and academic performance enhanced. Coleman emphasizes the meso- (community) level resources embedded in the closely knit social networks.

Coleman views social capital in functional terms and emphasizes the facilitative actions of the social structure as the defining feature of social capital. The mechanisms of the facilitation are not well explained, which has led to accusations that his theory is tautological (Portes, 1998: 5; Lin, 2001: 26), presumably because of his failure to distinguish resources within social structures from people's ability to acquire such resources. To illustrate, Portes gave an example where student A can get a loan from his/her resource-rich contact but student $\mathrm{B}$ cannot because the contact is equally poor or even poorer, even though the latter may be genuinely or even more strongly motivated to help than student A's contact. In such scenarios, Portes believes that Coleman would infer the presence of social capital in the former case but the absence of social capital in the latter case and that the outcome would be used to define the cause. In criticizing the 
tautological character in Coleman's definition, Portes seems to be suggesting that it is the possession of social networks rather than the ability to access the resources possessed by the network members which defines social capital. Yet he goes on to say that social capital refers to 'the ability to secure benefits through membership in networks or other social structures' (Portes, 1998: 8, emphasis added). ${ }^{4}$

Whilst Bourdieu's and Coleman's work on social capital is widely discussed in social capital literature due to their inspirations, it is Lin's and Putnam's work that has been more influential in the last decade. In the numerous papers and books, Lin has advanced his network-based theory of social capital, viewing it as an 'investment in social relations with expected returns in the marketplace' (Lin, 2001: 19). This, he holds, is consistent with the various renditions by all scholars who work in this area, including Bourdieu, Coleman and Putnam. More specifically, he sees social capital both as a concept and as a theory: 'As a concept, it represents investment in certain types of resources of value in a given society. As a theory, it describes the process by which capital is captured and reproduced for returns' (Lin, 2008: 51). Like Bourdieu and Coleman, Lin is mostly concerned with the instrumental effects of social capital (see contributions to Lin et al., 2001; Lin and Erickson, 2008), although he devotes considerable attention to what he calls the 'expressive' aspects of social capital such as solidarity, support and identity construction.

Lin's work is less controversial than that of Bourdieu or Coleman, partly because of the methodological feasibility. His major contribution to social capital research is the 'Position Generator' instrument, first developed in Lin and Dumin (1986). Basically, this is a small set of questions that can be included in social surveys. The questions contain a list of occupations and the respondent is asked whether he or she knows someone who has that job on the list (and the respondent could say any number on the list), and if they do, whether that person helped the respondent in finding his or her present job; the respondent is also asked about the relationship of the contact to him or her and how well they know each other (Lin, 2001: 124). The set of questions would only take 2-3 minutes in the survey time but contains a wealth of information including the volume, status, social distance and reachability (contacts in highest positions) which can be reconstructed from the job scores associated with a person's network ties, as well as the relationship and strength of the ties. As the respondents are randomly selected to represent the population and as the jobs on the list are designed to represent the occupational structure in a national or a sub-national context, so the social contacts should also be representative of the network structures in a given social milieu. Using the information yielded by the Position Generator would also make it possible to disclose the cascading character of social networks (Lin, 1986), from the innermost layer of intimate and confiding relations (binding ties of kin and confidants ${ }^{5}$ ), to the intermediary layer of information- and resource-sharing relations (bonding ties of friends, colleagues, neighbours or acquaintances), to the outer layer of general relations with shared membership and identity (bridging ties such as fellow church- or club-goers). Most importantly, it is an effective measure of the social stratification of network members at a nationally or sub-national level. More discussion of the measure, including its relative merits as compared with the name- and the resource-generator approaches, is found in Lin (2008: 54-8) and in several contributions to this volume, and it is not necessary to go into greater detail here.

Yet in spite of the economy and the ease of operation of the Position Generator in survey research, the instrument is rarely adopted in government-sponsored or 
long-standing academic surveys in the USA or Britain or China. ${ }^{6}$ It is usually found in purposely designed academic surveys of much smaller scales such as those reported in contributions to Lin et al. (2001), Lin and Erikson (2008) or Bennett et al. (2009). It is difficult to persuade designers of official surveys to adopt instruments for measuring sociological concepts which are deemed 'private goods'. This seems to form a sharp contrast to the warmth of reception, at least in the UK, of civic engagement measures in official surveys such as the Home Office Citizenship Survey series, which are deemed 'public goods' for civic revival.

Another reason may relate to the adequacy and the sensitivity of the measure in capturing what it intends to capture. For instance, the Position Generator asks the respondent whether he or she knew a person holding a job title on the list when looking for the present job. There are so many contingent factors in the job-seeking process that merely knowing a person with a job title on the list might reveal little on the causal factors (Mouw, 2003). Did that person really try to help? What kind of help was provided? Was the help of crucial importance? Was it direct or indirect help? And how much scope does the help provide for over- or under-reporting due to social desirability or social pressure in survey responses? For instance, Lin's (2001: 124) list includes, in China's context, job titles such as mayor, provincial or city party secretary, party secretary of a bureau or a factory, head of a bureau or public or private enterprise as the respondent's social contacts. For readers less familiar with China's socio-political structure, it is noted here that a party secretary is not a clerical worker in the ordinary sense of the word but someone of overwhelming power, influence and authority in Government organizations and state enterprises in China which is, by constitution, under the leadership of the Chinese Communist Party (CCP). Simply put, the party secretary holds the number 1 position in all non-private organizations. Thus the party secretary of a city has more power than the mayor, and this is the same at all levels of Party, Government and state organizations (including state and collective enterprises). China is also called a network society with intense inward-looking ties (Fei, 1947) where the importance of having the right social networks (guanxi) is well known and is felt in almost every aspect of socioeconomic life. A Chinese saying vividly captures the essence of guanxi (which also means 'whether something matters' in Chinese): if you have guanxi, there is no guanxi (nothing matters, as everything can be done easily); if you do not have guanxi, then there is guanxi (everything matters: nothing can be done easily). Nepotism, bureaucracy and 'blackbox operations' ('going through the back door') were all incidences of guanxi. Such practices are, of course, rarely endorsed in public discourse and hardly acknowledged by practitioners or beneficiaries, as they are the secret 'private goods' for the privileged. Things may be changing for the better but such social processes usually take a long time. The question is: would the respondent who is the beneficiary of such practices openly acknowledge it in front of an interviewer? Furthermore, it would be hardly surprising if, instead of having to look for a job, jobs were looking for them. By bestowing favours upon those who know a provincial or city or bureau party secretary, the favour-givers would only be too pleased, as this would enlarge and consolidate their own networks and increase their future benefits. Thus the recipient of the favours may have got the position without asking or even without prior knowledge. In such cases, the respondent might find it wiser to remain 'modest' rather than provide truthful answers. It is, therefore, unclear how the instrument could tap the full range of job-finding complexities. ${ }^{7}$ 
Notwithstanding the deficiencies, the Position Generator remains the best tool that is currently available for measuring the depths and widths of network resources and that can be used for research on the instrumental domain of social capital.

We now turn to Putnam, who is arguably the most influential scholar on social capital. He attracted controversy with his book on civic culture in Italy but it was his book on civic decline in the USA that became the centrepiece of the debate raging among almost all social science disciplines. In the 1993 book titled Making Democracy Work, Putnam showed that the northern and the southern parts of Italy had similar or identical institutions and financial investment but different levels of institutional performance in terms of identifying and addressing social needs, different efficiency in administrative processes, and different innovativeness in making public policies. The question was why there was such a difference in political performance in the different regions of the same country. He traced the sources in civic traditions. The rich and dynamic civic culture in the north makes it more likely for citizens to follow public debates, to participate in political processes, to abide by laws, to be less prone to corruption, and to have higher levels of trust and tolerance. Active involvement in civic associations generated norms which governed people's behaviours and which were transferable to the political arena, nourishing more effective political institutions. In short, civic organizations have value. As he succinctly puts it: 'Good government is a by-product of singing groups and soccer clubs' (Putnam, 1993: 176).

Right after his work on Italy, Putnam turned his attention to the civic health in his home country. He made a few publications on the topic in the ensuing years (Putnam, 1995a, 1995b, 1996) which caused 'a deluge' of criticisms (Putnam, 2000: 506). But he pressed on and presented his most systematic treatise on the subject in his 2000 book titled Bowling Alone. In this book, he amassed survey data from dozens of sources with millions of records covering half a century in the United States and including both formal and informal domains of social networks, and conducted meticulous analyses. The main findings, in the form of descriptive analyses such as means, frequencies, crosstabulations or correlations, are reported in the text, whilst the finer-tuned analyses are put in the notes. The book was written in a lively and yet serious manner, full of anecdotes, as his intention was to provide a broad-brush portrait of civic engagement in the USA for the past fifty years in a form accessible to the general public.

Putnam found a steady decline in both formal and informal social engagement in the USA. The findings caused a heated debate. It is interesting to note that in the dozens of books and hundreds or even thousands of papers that were published in its wake, many authors and commentators disagreed with him over numerous aspects of his claims but few, if any, questioned the quality of his data or the methodological rigour of his analyses (Fischer, 2005). Also noteworthy in this regard is his anticipation, six years prior to the publication, that while academics would always challenge the validity of his findings, public audiences would rarely ask whether it is true, 'because it rings so true to their experience' (Putnam, 2000: 509, emphasis added). One might add here that since academics do not live in a vacuum, their challenge, while expected as it is rooted in their professional ethics of engaging in independent and critical inquiry, might be viewed as an effort to reaffirm for themselves what they may also have perceived from their own experience.

For all the controversies and debates, Putnam's notion of social capital is a fairly simple one, which is not much different from that of the other three scholars, albeit 


\section{Handbook of research methods and applications in social capital}

with different angles of emphasis. Simply put, 'social networks have value' (Putnam, 2000: 19). This is essentially the same kind of statement as offered by Bourdieu, Coleman or Lin. Perhaps one reason for the controversies relates to the cause-effect relations in his formal definition of social capital. 'Social capital refers to connections among individuals - social networks and the norms of reciprocity and trustworthiness that arise from them' (Putnam, 2000: 19). ${ }^{8}$ Here social networks are seen as causes and the norms as effects. But again this is little different from Coleman's emphasis on the norm-compliance benefits from closed networks, or indeed only slightly different from Bourdieu's emphasis on networks possessing 'economic, cultural or symbolic' capitals (1986: 52), or Lin's emphasis on contacts having 'power, wealth, or status' (2008: 52). The difference might be better seen as attributing to the different outcome areas to which the concept is applied rather than to the intrinsic value attached to the networks. Sociologists' main interest is in using social capital to explain educational and occupational mobility at the individual level whereas political scientists are keen to use it to account for social cohesion and political governance at the collective level. However, his notion of trust as an outcome of civic engagement, inspired by Tocqueville (1835 [1965]), may be more debatable. It is not certain whether civic engagement generates norms of trust or whether trusting people are more likely to engage in such activities in the first place (Li et al., 2005; Uslaner, 2008a, 2008b; and Sturgis et al., this volume). Or, there may be both a self-selection effect and a positive relationship between trust and civic participation. More trusting and trustworthy people may be more likely to join civic associations in the first place but even those who are not particularly trusting may be channelled to civic activities because their friends are there and, in the process of working together on community problems, they may become more cooperative and more trusting. Such effects are hard to unravel. For instance, Li et al. (2005) show the self-selection but not the channelling effects.

Unlike in his 1993 book, Putnam devoted much attention to informal social involvement in addition to formal civic engagement in the 2000 book. 'When philosophers speak in exalted tones of "civic engagement" and "democratic deliberation", we are inclined to think of community associations and public life as the higher form of social involvement, but in everyday life, friendship and other informal types of sociability provide crucial social support' (Putnam, 2000: 95). He also initiated some new terms which have been much used in social capital research but which have also caused much confusion because he did not provide specific guidance on how to measure and delineate them. For instance, he calls those in formal civic engagement 'machers', those in informal involvement 'schmoozers', and people in both types 'all-round citizens' (2000: 93-4); and he also says that people with exclusive ties (such as those in ethnic fraternal organizations or church-based women's reading groups) have 'bonding' social capital and those with inclusive ties (such as those in civil-rights movements or youth service groups) have 'bridging' social capital. These examples pertain to the formal civic domain and it is not clear how to differentiate bonding and bridging ties among schmoozers. He suggested that informal groups may be simultaneously bridging and bonding, such as internet chat groups comprising people from different localities, of different ages and with different religious affiliations while being homogeneous in terms of educational experience and ideological orientation. While the distinction between machers and schmoozers is very important for social capital research, the differentiation of friends, colleagues and 
neighbours into bonding and bridging ties is harder to make: "bonding and bridging are not "either-or" categories . . but "more or less" dimensions' (2000: 23). ${ }^{9}$ But he is more specific on the functions of the different ties: "Bonding social capital is . . . good for "getting by," but bridging social capital is crucial for "getting ahead"" (2000: 23), which is reminiscent of the theses in the instrumental tradition such as those on the strength of weak ties or of structural holes (Granovetter, 1973; Burt, 1992). While the informal ties have such functions, how does membership in a women's reading group (bonding) or in a youth service group (bridging) help one to get by or get ahead?

The above is a brief review of the vast literature by and on the leading authors in relation to social capital. Overall, there are both similarities and differences in their theoretical accounts, with similarities overweighing differences. In terms of measurement, Lin's Position Generator is arguably the best instrument currently available for measuring the social positions of informal connections while Putnam's distinction between machers and schmoozers is of considerable value in distinguishing between formal and informal engagement. There is no clear guidance for assessing the amount and quality of resources such as power, influence or wealth in informal networks, or for differentiating between bonding and bridging ties in formal and informal networks (although Demireva and Heath make a good effort in this volume). There are many other aspects which have not been covered in the review, such as the dark side and the externalities of social capital, the borderline between spontaneously and formally organized activities, the new forms of social engagement through social media (such as Facebook and Twitter), and the finer-grains of expressive and civic values to which social capital can be applied.

\section{THE STATE OF OUR CIVIC HEALTH: WITHERING AND HUNKERING?}

As noted above, it is Putnam's rather than the other three scholars' work on social capital that has attracted most controversy in the last twenty years. Putnam provided a bewildering range of data documenting the decline in both formal and informal social connectivity in the USA from bowling leagues, labour unions, fraternal associations (1995b: 665), to social trust, charitable giving, voting in presidential elections, newspaper reading, weekly church attendance, and to social visiting, picnics or home meals with friends (2000: passim). 'Despite rapid increases in education that have given more of us than ever before the skills, the resources and the interests that once fostered civic engagement ... Americans have been dropping out in droves, not merely from political life, but from organized community life more generally' (Putnam, 2000: 64).

Is it really true that Americans are becoming less civic-minded? Or is the story of withering America too roughly sketched, based largely upon simple descriptive analysis rather than on sophisticated statistical modelling? Or is the declining civicness another instance of American 'exceptionalism'? As Putnam had anticipated, critics would rush to test and scrutinize every aspect of his claims. Indeed, critical evaluations started to emerge even before the advent of his 2000 book (Brehm and Rahn, 1997). We give two examples here, one on the formal and the other on the informal domain of social involvement, by Paxton (1999) and McPherson et al. (2006) respectively.

Paxton (1999) used the General Social Survey (GSS) covering twenty years from 1975 
to 1994. Using sophisticated modelling techniques on two of Putnam's key elements of social capital, trust and associations, Paxton showed that all three indicators of trust in individuals (fairness, trust and helpfulness) were on a steady decline, by around twenty percentage points in as many years covered. Trust in institutions (education, religion, executive and legislature) was also on the decline, albeit by a smaller amount. Combining trust in individuals and institutions and in civic associations as a summary measure, she again finds a steadily declining trend, by around seventeen percentage points. The evidence suggests support to Putnam's thesis of dissipating civicness in American society.

Turning to informal social connection, McPherson et al. (2006: 369) provided the evidence that both kin and non-kin ties in the core discussion networks were becoming smaller from 1985 to 2004, again using the GSS data. There was more education over the two time points but both kin and non-kin ties fell in proportionally higher terms with greater education, supporting Putnam's argument that more skills did not help prevent the fall in informal social capital. It took thirteen years of education (high school) to have the same number of kin and non-kin ties in 1985 but seventeen years (college) to have the same number of kin and non-kin ties in 2004. Even people with twenty years of education (postgraduates) did not have as many non-kin as kin ties in 2004. Americans seem to be increasingly withdrawing into their own spheres. Why is it so? Putnam (2007) suggests a possible reason (migration) which he says may lead to the 'hunkering down' but this is highly contested (Letki, 2008; Laurence, 2011).

While the research on social capital in the USA is impressive and is largely supportive of the 'Bowling Alone' story, one might think that this is US-specific and that other countries may not share the same experience. Indeed, a highly influential paper was published in 1999 by Peter Hall, showing the opposite scenario in Britain. In contrast to the USA, Hall holds that civic life has enjoyed a vibrant and healthy growth in the last fifty years in the UK. However, amidst this general vibrancy, Hall (1999: 423) discerns a growing trend of social stratification, with the middle class enjoying more civic engagement than the working class although all classes had more associational membership in 1990 than in 1959. As the middle class has been growing in size, social capital in Britain has, according to Hall, been well-sustained.

Hall's analysis suggests that the 'Bowling Alone' scenario as depicted by Putnam may indeed be US-specific. Yet Hall's claims were also contested. ${ }^{10}$ Using the 1972 Social Mobility Inquiry (SMI) and the 1999 British Household Panel Survey (BHPS), Li et al. (2003) found an overall decline in civic engagement in Britain. Their analysis supports Hall's findings of a growing social stratification in civic engagement, but the crucial point is that working-class civic engagement has fallen beyond reasonable doubt and that by the professional-managerial class has been only barely maintained. The reason for this is traced to the structural changes including the collapse of traditional industries such as coal-mining and car manufacturing, which erodes the organizational basis of trade unions.

Research on informal social ties also shows declining social connectivity in the UK. Pahl and Pevalin (2005) study the trends of friendship using data from the BHPS. Similar to McPherson et al.'s (2006) findings in the US case, Pahl and Pevalin find that, in the tenyear period covered (1991-2000), most of the respondents became more inward-looking. Their circle of friends became smaller and the composition more kin-based. In short, Britons have 'hunkered in' just as Americans have 'hunkered down' (Putnam, 2007). 
Another study in this regard was conducted by Grenier and Wright (2006) in which they also find the basis of Hall's optimism rather shaky.

Overall, most researchers in the area seem to share the view that social capital has declined in Britain and the USA, and that in terms of both the formal and informal social network.

\section{A FRAMEWORK OF USING SOCIAL CAPITAL FOR SOCIOLOGICAL ANALYSIS}

As discussed above, there is a general consensus both among the leading scholars and among other researchers in the field that social capital is fundamentally concerned with the resources embedded in social networks but one has to invest in the relations in order to be able to access and mobilize the resources. There is a difference in focus with regard to the domains of application, with sociologists (Bourdieu, Coleman and Lin) stressing the instrumental value at the micro and meso levels and political scientists such as Putnam emphasizing the civic (collective) value at the macro level, although both Lin and Putnam go to great lengths to explain that social capital can be of value to both individuals and communities at local and higher levels. Another difference pertains to the existing or potential resources within one's networks, with Bourdieu and Lin focusing on socioeconomic-symbolic factors such as money, power or influence that are possessed by the network members, whereas Coleman and Putnam pay special attention to the norms of reciprocity, trustworthiness and generosity that are generated in the process of conducting joint activities by network members that can benefit both group members and onlookers (the externalities of social capital). All leading theorists agree that social networks do not come to one's doorstep. Rather, people need to cultivate social relations, and this needs socioeconomic-cultural resources. The degree to which people have such resources at their disposal for the investment would in general correspond to the volume, amount and quality of resources in the social networks they have, as Bourdieu pointed out. The differential access to social networks and associated resources together with the different functions of networks for the different social groups therefore constitutes a research programme for conducting sociological analysis on social capital in the stratification tradition and, by extension, in the civic tradition.

Figure 1.1 shows a framework of using social capital in sociological research. Here social capital is treated both as an outcome and as a mediating variable. As an outcome variable, we would explore the socio-demographic determinants. Apart from people's own class and educational positions, it is important to analyse the role of origin class. Social capital starts with family, which is a theme common in the writings of Bourdieu, Coleman and Lin. Also important is the role of cultural identity in undergirding social capital such as that between ethno-religious affiliation and charitable giving (Regnerus et al., 1999; Putnam, 2000; Putnam and Campbell, 2010).

Social capital has a formal and an informal domain which may be closely related (as indicated in the dotted arrow in the diagram) in the sense that machers are more likely to be schmoozers and vice versa. Within both spheres there are bonding and bridging ties, although how to differentiate and measure such ties in a meaningful and effective manner is, as noted above, a difficult task. We have a few contributions in the 


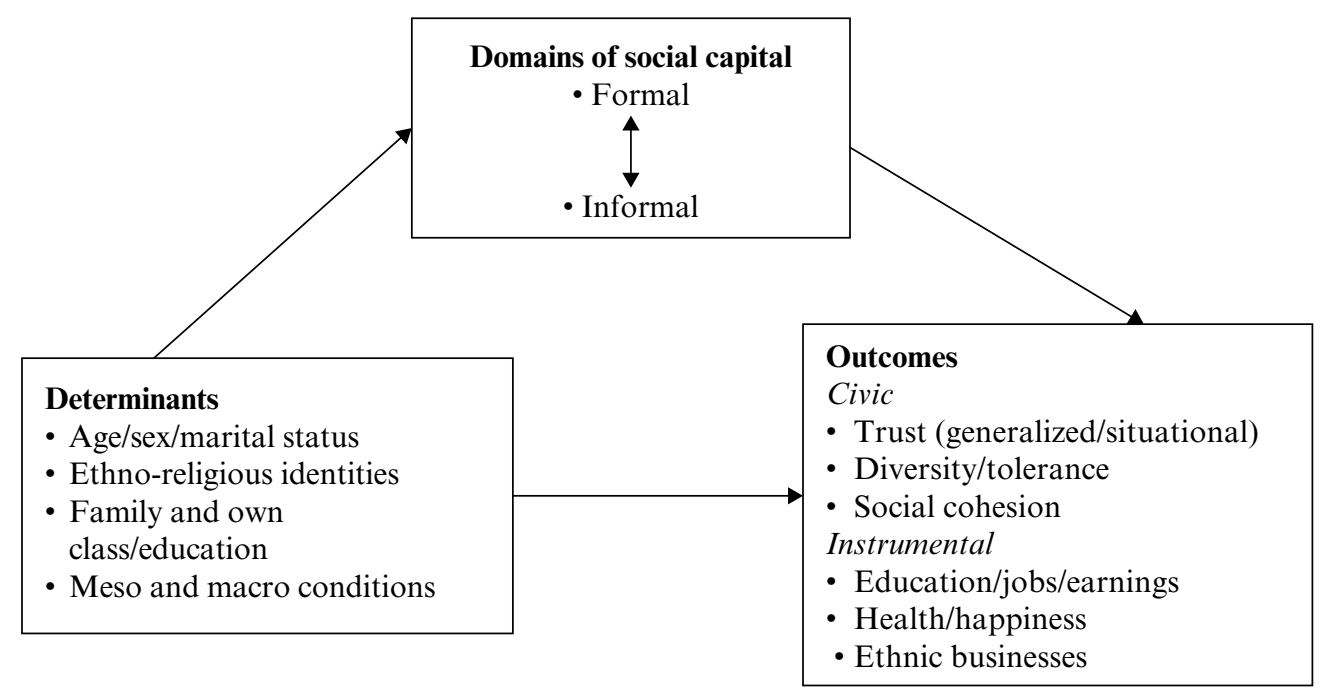

Figure 1.1 A framework of social capital analysis

volume devoted to this end. Two other factors are worth considering. First, with regard to Bourdieu's emphasis on the interrelated nature of social and cultural resources which forms a web of class advantages and disadvantages, we need to link cultural practice to formal and informal social connectivity. The research on cultural consumption suggests an omnivore-univore scenario (Chan and Goldthorpe, 2007) but the effects of class, including origin class, on cultural consumption and the association of cultural practice with formal and informal social networks have been little explored. The second issue pertains to the channelling and fostering effects of formal and informal social involvement, which would be most clearly manifested in philanthropic behaviour. For instance, if one's friends are organizing a charitable event, one would be more inclined to donate (Putnam and Campbell, 2010). The exact causal direction between social connection and generosity is like a chicken-and-egg issue but what is of a primary concern for sociological analysis in this regard is the need to establish firmly whether a substantial and significant association does exist between these factors. Our volume also contains analyses in this regard.

Lin's Position Generator has, as discussed above, been a major innovation in measuring the resources embedded in informal social networks. The strength of tie is hard to measure due to the dearth of data in general social surveys or even in Lin's own design as noted earlier. But the cascading character could be assessed using data on the relationship of the ties to the respondent. The question then is concerned with the position of 'friends': are 'friends' as reported by survey respondents closer to kin as intimate and confiding relations, or in a more general sense similar to other non-kin ties? Another issue with the Position Generator is that since it is the individual occupations that are taken as indicators of people's network resources, should we take the occupations as measuring the contact's class position or status/prestige? These are not mere methodological niceties but may contain important conceptual implications. Most of the 
empirical analyses in the field take the status approach since it is easier to use continuous measures for multiple ties, but the class approach, which takes the contacts' positions as categorical variables, may reveal unique network features that are masked in the status approach. The issues are also addressed by contributors to this volume.

With regard to the effects of social capital, our contributors measure both the civic and the instrumental (including the 'expressive') outcomes. The formal and informal domains of social networks have different implications for the outcome areas, with the formal social engagement more directly related to the civic sphere and the informal social connection more closely related to the instrumental sphere. With regard to the formal engagement-civic link, we focus on the channelling and fostering effects of formal civic engagement on generalized and situational trust (the latter including both personalized and meso-level, namely, neighbourhood, trust), diversity and tolerance and social cohesion. In recent years, there has been a debate arising from Putnam's (2007) controversial paper in which he says that even though migration (or, more importantly for our present purposes, immigration) is good in the long run, it may have negative effects on social cohesion in the short run, in that it can drive down social trust. Not only inter-, but even intra-ethnic trust suffers in the event of a sudden onset of large numbers of newcomers. Diversity, in short, makes people 'hunker down'. Given this, the relationship between poverty, diversity and trust becomes an important research theme with considerable policy implications, and this importance assumes greater salience by the presence of large and increasing numbers of first, second and higher generations of ethnic minority members in advanced capitalist societies such as Britain. Does civic engagement lead to greater trust and tolerance? Is diversity or deprivation more closely related to community cohesion? Is there a close relationship between bonding and bridging in both formal and informal domains? Several chapters in the volume are devoted to exploring the complicated relationship between immigration, diversity, deprivation and community cohesion.

As the 'civic virtue' yields public goods, the benefits to both the volunteers and wider society are continuing to attract the interest of social scientists. Equally, the instrumental value of informal social networks, particularly in the classical domain of educational attainment, access to jobs and earnings in the labour market, still engages the attention of sociologists. Also important is the attention to the 'expressive' domain of social capital, that is, support, sympathy, and solidarity as generated in informal networking which reduces stress, improves health and enhances happiness. Finally, social capital within ethnic communities in terms of mutual acquaintance and friendship, information sharing, emotional and financial help and support is of crucial importance to the survival, settlement and success of newly arrived immigrants, with special regard to employment, and to the set-up, operation and growth of ethnic niche businesses. These issues are also covered by our contributors.

The chapters in the volume reflect the thinking in the framework of Figure 1.1. We asked the contributors who are experts in the field to conduct analyses on social capital using the best datasets they could avail themselves of and the most appropriate methods for addressing their specific research questions. No doubt each dataset would have unique characteristics and no dataset contains all the information that one would ideally wish to have. Thus our chapters reflect the data availability for the research questions as well as our contributors' research interests. We also have some chapters that are based 
on qualitative research. It was not the intention to adopt a standardized procedure in terms of the construction of the explanatory or the outcome variables, or of the modelling techniques, as are found in some other edited volumes such as those on social mobility in the developed countries, or on ethnic penalty in the labour market or in educational achievement (Breen, 2004; Heath and Cheung, 2007; Heath and Brinbaum, 2014).

We now give a brief summary of the key findings in the chapters. Li, Savage and Warde (Chapter 2) show that people's mobility trajectory, parental education and cultural practice (which serve as prior factors), and informal networks (which serve as concurrent factors) are all significantly related to different domains of cultural practices. While the most advantaged (members of the intergenerationally stable salariat) are more omnivorous than the least advantaged (the intergenerationally stable working class), the key finding is the unrivalled ability of the former to enjoy the 'legitimate' (high-brow) forms of cultural activities. The difference is, therefore, not simply a more-or-less matter as shown in the omnivore-univore debate but a qualitative one which has received rather little attention in the literature, revealing the 'hidden injuries' of class. In other words, social and cultural capital practices are exclusionary strategies rooted in family origins. Following this is the chapter on generosity, namely, giving time, effort and money as interrelated domains of civic culture in contemporary Britain. In contrast to the themes found in the US literature on 'flat-line' or U-shaped giving, Li (Chapter 3) shows that the poor give more in relative but not in absolute terms than the rich in Britain and that Muslims, who are the poorest group in the country (Heath and $\mathrm{Li}, 2014$ ), actually give the most to charitable causes. Volunteering, informal help for others in need and charitable giving are all significantly related to one another and mutually reinforcing. While the exact causal direction may be like a bowl of spaghetti, it is more plausible to think of social networking as engendering the channelling and fostering effects on charitable behaviour than the other way round.

With regard to the civic domain of social capital application, we have several chapters. Uslaner (Chapter 4) shows that a binary approach to the generalized trust question is actually more effective than a more fine-tuned Likert-scale question. Sturgis and his colleagues (Chapter 5) show that there is a self-selection tendency for trusters to join civic organizations rather than vice versa and they suggest that trust may be a stable trait arising from early socialization. Safe home and neighbourhood environments play an important role in establishing the sense of security, fostering the norms of trust and trustworthiness, and cultivating their self-confidence when people are young, and once established, such traits may stay and manifest themselves in an active participation in social activities in adult life. In their exploration of the association between diversity and tolerance in Canada, Côté, Andersen and Erickson (Chapter 6) show a complicated picture, namely, that contact does make a difference, but when resource-competition is involved, tolerance will be less likely to occur. The contact and the conflict theories are not thus in conflict. This finding is echoed by Cutts and Fieldhouse (Chapter 7), whose sophisticated US-UK comparison suggests that while diversity tends to erode social cohesion, there are various countervailing effects so that contact and conflict may happen simultaneously. In other words, the effect of social capital and diversity upon tolerance and community cohesion is contingent upon contextual factors such as the economic situation at the local and national levels, as indicated above.

Using a unique dataset on ethnic minority members' electoral behaviours, Demireva 
and Heath (Chapter 8) are able to measure both bonding and bridging social ties in informal and formal social connections, and both among the different ethnic groups and across the first and the second generations in Britain. They find a decline in informal bonding among the second-generation ethnic minority groups and a mutually supporting role between bonding and bridging. The implication is that neither bonding nor bridging should be privileged as they play complementary roles. How do social-connection and trust relate to each other in different communities? Laurence (Chapter 9) shows that people in poorer neighbourhoods may be well connected but not less trusting, whereas those in more affluent areas may be more trusting but less connected, a finding that goes beyond Putnam's (2007) thesis on the erosive effect of diversity on social cohesion.

The other chapters in the volume are concerned with the instrumental aspect of social capital. As Lin's Position Generator (PG) plays a prominent role in measuring informal social capital, we first present some analyses on the relative merits of the status versus the class approaches to measuring the contacts' jobs, the role of 'friends' in assessing the cascading profiles of people's personal networks, and other ways of gauging such measures where the PG is not directly used. With regard to the first point, Verhaeghe and $\mathrm{Li}$ (Chapter 10) show that the class approach actually yields more powerful and meaningful results, although it is not likely to be widely adopted due to the difficulty in operation. As for the second point, Li, Heath and Devine (Chapter 11) find that 'friends' as reported by survey respondents are not likely to be 'confidants' with a disclosing intimacy but are more similar to other non-kin relations. Furthermore, they find that, among the non-kin ties, people's mobility trajectory has a notable impact on bonding and bridging ties. People who have travelled an uphill journey, namely those who have achieved intergenerational upward mobility, tend to have a larger number and a more diverse range of bridging and linking ties, and those who have stayed in the upper echelons of the social hierarchy, namely those who are intergenerationally stable in the professional-managerial salariat, have contacts in highest status constituting clearly bonding relations. Birds of a feather perch together. As for the third point, Griffiths and Lambert (Chapter 12) show that although the Position Generator is hardly adopted in 'official' social surveys, a wealth of information concerning the social positions of network members is actually available but needs meticulous work to 'unearth', as they have done using the British Household Panel Survey. The issues addressed in these three chapters are not only methodological but carry important substantive implications for social capital research.

As discussed above, Lin holds that informal social networks have not only instrumental but also expressive values. The latter is evidenced in our country studies in Australia and Britain. Of particular note here is the finding by Huang and Western (Chapter 13) that it is the quality rather than the quantity of discussion networks that is of importance to people's life satisfaction in Australia. Kin, friends and colleagues play an indispensable role in emotional support and social companionship. This applies not only to the general population but to ethnic minority groups, albeit with different effects. Using a combination of qualitative and quantitative methods, Bécares and Nazroo (Chapter 14) show that ethnic density does not play the same role for health for all ethnic groups in England. For Indians and Pakistanis, a positive effect was found but this was not the case for black and Bangladeshi groups. They offer some explanations for this, which would appear as counterintuitive at first sight but are on reflection quite plausible. 
Finally, with regard to the instrumental effects of social capital on educational achievement and labour market position, our authors show a generally positive although sometimes mixed picture. Fiel, Shoji and Gamoran (Chapter 15) find a mixed result concerning social capital and grade retention in American schools: positive in San Antonio and negative in Phoenix, suggesting, as the authors believe, that social capital has an enabling role in that it can help actors to negotiate critical and contentious decisions in the educational careers. Social capital effects are shown in qualitative research too. Field (Chapter 16) shows that supportive family relations are highly conducive to adult education, echoing Putnam's (2000) observation that the best social capital lies in the family. Interestingly, social capital not only helps the 'subjects' but also the researcher in smoothing the research process. In her chapter, Dhillon (Chapter 17) tells a fascinating story that, by maintaining good relations with her interviewees who were key stakeholders in different organizations, she was able to conduct the research in a more efficient way. Rodríguez Menés and Donato (Chapter 18) find a positive effect of social capital. Using the PISA data of 2006, they show that social capital enhances children's cognitive development in the 28 OECD countries. In terms of social capital's effects on labour market outcomes, our colleagues show that social networks continue to play a significant role in the reform era in China. As private and public sectors co-exist in China's economy, Bian and his colleagues (Chapter 19) find that those with social contacts spanning different institutions are more advantaged and have higher earnings than those with only within-sector social ties. People with bridging and linking social capital are rewarded by their employing organizations for having well-connected guanxi. With the deepening reforms and a growing share of the private sector, the importance of social capital is increasingly recognized. Yet, as Zhang and Zhang (Chapter 20) show, the marketization has also resulted in a declining return to social capital. The reforms have offered greater freedoms and mobility chances but employers have also placed greater importance on productivity potentials. In this sense, continued reforms might bring some real hope of meritocracy in China. Last but not least, Molina and his colleagues (Chapter 21) show that the Position Generator method can be effectively used to measure upward social mobility within ethnic enclaves for both the entrepreneurs and their co-ethnic employees working in Pakistani shops in Barcelona and Indian shops in Lloret, Spain.

Overall, we find that social capital is a powerful tool that can enhance our understanding of the interrelated nature of our socioeconomic-cultural lives. We believe that this book has made real progress in understanding the mechanisms rather than just depicting associations and descriptive trends as is characteristic of most previous research. The mechanisms pertain both to factors generating the inequality of formal and informal social involvement and to ways in which both kinds of involvement impinge on outcomes in the civic, instrumental and expressive domains. For both types of mechanisms, we have been able to document the substantial differences between different social groups in their ability to access and to reap the benefits of social capital. Thus, for example, we find strong mobility trajectory effects on both formal and informal social involvement and on cultural practice, the channelling and fostering effects of both forms of social engagement on philanthropic behaviour, and the significant roles played by formal and informal social engagement on trust, tolerance, community cohesion, educational and occupational attainment, health and quality of life, and ethnic entrepreneurism. 
We hope that our analysis of the determinants, manifestations and consequences of social capital has made a useful contribution to social capital research, but we also acknowledge that there are many other aspects of social capital generation and functioning that await further exploration with more powerful datasets and analytical methods. We believe that our findings will present a major challenge both to other social capital researchers interested in explaining the causes, interrelated domains and effects of social capital and to governments and policy-makers who have responsibility for ensuring social equality and community cohesion.

\section{NOTES}

1. Some scholars prefer the term 'resource' to that of 'capital'. For instance, when explaining the relative advantages associated with different class positions, Goldthorpe (1987: 99) refers to economic, cultural and social resources (see also Goldthorpe, 2007). The concern seems to be mainly with the implied 'economism' associated with 'capital'. There are also debates as to whether 'social capital' is a useful concept at all. Fine claims that it is 'a totally chaotic, ambiguous, and general category' (2002: 115) while Woolcock holds that it 'gives classical (and contemporary) sociological themes a voice they would not otherwise have' (2001: 14). While acknowledging different points of view, it seems fair to say that most researchers in the field accept Hanifan's position that the term is used only 'in a figurative sense', referring to 'good will, fellowship, sympathy, and social intercourse among the individuals and families who make up a social unit' (Hanifan, 1916, cited in Putnam, 2002: 4).

2. See, for instance, Goldthorpe (2007), for a powerful attack on Bourdieu.

3. We can find some indirect evidence for this. An analysis of the Understanding Society survey (waves 1-3 combined for 2009-11) shows that, for men under age 35 and with only lower secondary education (O-levels or below), 25 per cent from higher professional and managerial (salariat) families are found in salariat jobs but only 10 per cent from families in routine manual positions are found in such jobs. On the other hand, only 14 per cent of the former but 29 per cent of the latter are found in routine jobs. Thus the class difference for the equally poorly qualified young men is clearly shown, with an odds ratio of 4.8:1.

4. In criticizing Coleman, Portes (1998: 5) holds that 'it is important to distinguish the resources themselves from the ability to obtain them by virtue of membership in different social structures' and that 'equating social capital with the resources acquired through it can easily lead to tautological statements', but this seems in clear contradiction of his subsequent emphasis on the actor's ability to secure benefits as the criterion for testing whether one has social capital. Does an inability to acquire benefits from highly motivated but resource-poor contacts count as lack of social capital? Similarly, Lin stresses the accessibility and mobilizability of resources in the social networks as the most important feature of social capital (Lin, 2008: 51) but he does not explain in what sense his 'accessibility' or 'mobilizability' differ from Coleman's 'facilitation'.

5. It is not clear how the 'confidant' ties could be captured by the Position Generator (PG) measure. The PG items on the strength of ties include 'How long have you known each other?' and 'Do you know each other well?' (Lin, 2001: 124). Someone may have known a person for a long time and know him/her very well but they may not like each other at all. Mere length of time or even depth of knowledge does not make people close friends, let alone confidants. Jamieson (1998) describes the confidant relationship as one characterized by 'a disclosing intimacy' and Pahl (2000) sees close friendship as the formation and cultivation of social ties signalling a concordance between reason, passion and desire. Such features as involving disclosing intimacy and concordance would be hard to capture using survey items.

6. For instance, there are dozens of national representative social surveys conducted by government organizations or academic communities listed on the UK data archive's website but in only two years of the Taking Part series (2006/7 and 2007/8) do we find the adoption of the Position Generator (PG) measure. To the best of our knowledge, it is not used in the American Community Survey (ACS), the Current Population Survey (CPS) or the General Social Survey (GSS) in the USA, or the General Household Survey (GHS), the Labour Force Survey (LFS) or the British Household Panel Study (BHPS) and its successor - Understanding Society (USoc) in the UK, or the China General Social Survey (CGSS), although in the CGSS, it is partially implemented in 2008, with the contacts' jobs omitted.

7. An ancient Chinese saying captures nepotism quite well: when a man gets to the top, even his pets (chickens and dogs) ascend to heaven, meaning that all his friends and relatives will get benefits. 


\section{Handbook of research methods and applications in social capital}

8. In his earlier work, Putnam defines generalized reciprocity as 'a continuing relationship of exchange that is at any given time unrequited or imbalanced, but that involves mutual expectations that a benefit granted now should be repaid in the future' (Putnam, 1993: 172).

9. Woolcock (2001: 13) had another concept called 'linking social capital' but Putnam (2004: 669-70) believed that it is part of bridging which had both vertical and horizontal dimensions. It seems that the concept of linking social capital is useful, especially in development studies where government involvement is crucial for reducing poverty through coordination of efforts by various 'stakeholders' although it is also implied in the thesis of strengths of strong ties. For instance, both information and reference letters by social contacts are important for the job-seeker because the contacts are linked in one way or another to the prospective employer.

10. A possible reason for the optimistic picture that Hall paints on British civic health may be due to the data sources he used, namely, opinion polls, where the sampling procedure is not as rigorous as adopted in government and academic surveys, and where variables such as class are not so well measured as they are in standard British practice.

\section{REFERENCES}

Bennett, T., M. Gayo-Cal, M. Savage, E.B. Silva, A. Warde and D. Wright (2009), Culture, Class, Distinction, London: Routledge.

Bourdieu, P. (1986), 'The forms of capital', in A.H. Halsey, H. Lauder, P. Brown and A.S. Wells (eds) (2006), Education: Culture, Economy, Society, Oxford: Oxford University Press, pp. 46-58.

Breen, R. (ed.) (2004), Social Mobility in Europe, Oxford: Oxford University Press.

Breen, R., R. Luijkx, W. Müller and R. Pollak (2009), 'Non-persistent inequality in educational attainment: evidence from eight European countries', American Journal of Sociology, 114(5), 1475-521.

Brehm, J. and W. Rahn (1997), 'Individual-level evidence for the causes and consequences of social capital', American Journal of Political Science, 41(3), 999-1023.

Burt, R. (1992), Structural Holes, Cambridge, MA: Harvard University Press.

Chan, T. and J.H. Goldthorpe (2007), 'Class and status: the conceptual distinction and its empirical evidence', American Sociological Review, 72, 512-32.

Coleman, J.S. (1988), 'Social capital in the creation of human capital', American Journal of Sociology, 94, S95-S120.

Coleman, J.S. (1990), Foundations of Social Theory, Cambridge, MA: Harvard University Press.

Devine, F. (2004), Class Practices: How Parents Help Their Children Get Good Jobs, Cambridge: Cambridge University Press.

Fei, X. (1947), Xiangtu Zhongguo, Beijing: Sanlian Shudian; English translation by Gary Hamilton and Wang Zheng (1992), From the Soil: The Foundations of Chinese Society, Berkeley, CA: University of California Press.

Field, J. (2008), Social Capital, 2nd edn, Abingdon: Routledge.

Fine, B. (2002), 'They $\mathrm{f}^{* * \mathrm{k}}$ you up those social capitalists', Antipode, 796-9.

Fischer, C.S. (2005), 'Bowling Alone: what's the score?', Social Networks, 27, 155-67.

Goldthorpe, J.H. (with C. Llewellyn and C. Payne) (1987), Social Mobility and Class Structure in Modern Britain, Oxford: Clarendon Press.

Goldthorpe, J.H. (2007), "Cultural capital”: some critical observations', Sociologica, 2007(2), doi: $10.2383 / 24755$.

Goldthorpe, J.H. and M. Jackson (2008), 'Education-based meritocracy: the barriers to its realisation', in A. Lareau and D. Conley (eds), Social Class: How Does it Work?, New York: Russell Sage Foundation, pp. 93-117.

Granovetter, M.S. (1973), 'The strength of weak ties', American Journal of Sociology, 78(6), 1360-80.

Grenier, P. and K. Wright (2006), 'Social capital in Britain: exploring the Hall Paradox', Policy Studies, 27(1), 27-53.

Hall, P. (1999), 'Social capital in Britain', British Journal of Political Science, 29, 417-61.

Halpern, D. (2005), Social Capital, Cambridge: Polity.

Heath, A. and Y. Li (2014), 'Review of the relationship between religion and poverty', research report for Joseph Rowntree Foundation, York: JRF, pp.33-6, available at http://www.jrf.org.uk/sites/files/jrf/ Reducing-poverty-reviews-FULL.pdf\#page $=6$.

Heath, A.F. and Y. Brinbaum (eds) (2014), Unequal Attainments: Ethnic Educational Inequalities in Ten Western Countries, Proceedings of the British Academy 196, Oxford: Oxford University Press for the British Academy. 
Heath, A.F. and S.Y. Cheung (eds) (2007), Unequal Chances: Ethnic Minorities in Western Labour Markets, Proceedings of the British Academy 137, Oxford: Oxford University Press for the British Academy.

Jackson, M., J.H. Goldthorpe and C. Mills (2005), 'Education, employers and class mobility', Research in Social Stratification and Mobility, 23, 3-34.

Jamieson, L. (1998), Intimacy: Personal Relationships in Modern Societies, Cambridge: Polity.

Lareau, A. and E. Weininger (2003), 'Cultural capital in educational research: a critical assessment', Theory and Society, 32, 567-606.

Laurence, J. (2011), 'The effect of ethnic diversity and community disadvantage on social cohesion: a multilevel analysis of social capital and interethnic relations in UK communities', European Sociological Review, 27(1), 70-89.

Letki, N. (2008), 'Does diversity erode social cohesion? Social capital and race in British neighbourhoods', Political Studies, 56, 99-126.

Li, Y., A. Pickles and M. Savage (2005), 'Social capital and social trust in Britain', European Sociological Review, 21(2), 109-23.

Li, Y., M. Savage and A. Pickles (2003), 'Social capital and social exclusion in England and Wales (1972-1999)', British Journal of Sociology, 54(4), 497-526.

Li, Y., M. Savage and A. Warde (2008), 'Social mobility and social capital in contemporary Britain', British Journal of Sociology, 59(3), 391-411.

Lin, N. (1982), 'Social resources and instrumental action', in P.V. Marsden and N. Lin (eds), Social Structure and Network Analysis, Beverly Hills, CA: Sage, pp. 131-45.

Lin, N. (1986), 'Conceptualizing social support', in N. Lin, A. Dean and W. Ensel (eds), Social Support, Life Events and Depression, Orlando, FL: Academic Press, pp. 17-30.

Lin, N. (2001), Social Capital, Cambridge: Cambridge University Press.

Lin, N. (2006), 'Social capital', in J. Beckert and M. Zafirovski (eds), International Encyclopedia of Economic Sociology, London: Routledge, pp. 604-12.

Lin, N. (2008), 'A network theory of social capital', in D. Castiglione, J.W. Van Deth and G. Wolleb (eds), The Handbook of Social Capital, New York: Oxford University Press, pp. 50-69.

Lin, N. and M. Dumin (1986), 'Access to occupations through social ties', Social Networks, 8, 365-85.

Lin, N. and B. Erickson (eds) (2008), Social Capital: An International Research Program, Oxford: Oxford University Press.

Lin, N., K. Cook and R. Burt (eds) (2001), Social Capital: Theory and Research, New Brunswick, NJ: Aldine Transaction Publishers.

Lin, N., W.M. Ensel and J.C. Vaughn (1981), 'Social resources and the strength of ties: structural factors in occupational attainment', American Sociological Review, 46, 393-405.

McPherson, M., L. Smith-Lovin and M. Brashears (2006), 'Social isolation in America: changes in core discussion networks over two decades', American Sociological Review, 71(3), 353-75.

Mitchell, J.C. and F. Critchley (1985), 'Configurational similarity in three class contexts in British society', Sociology, 19(1), 72-92.

Mouw, T. (2003), 'Social capital and finding a job: do contacts matter?', American Sociological Review, 68(6), 868-98.

Pahl, R. and D. Pevalin (2005), 'Between family and friends: a longitudinal study of friendship choices', British Journal of Sociology, 56(3), 433-50.

Pahl, R.E. (2000), On Friendship, Cambridge: Polity.

Paxton, P. (1999), 'Is social capital declining in the United States? A multiple indicator assessment', American Journal of Sociology, 105(1), 88-127.

Portes, A. (1998), 'Social capital: its origins and applications in modern sociology', Annual Review of Sociology, 24, 1-24.

Putnam, R.D. (1993), Making Democracy Work: Civic Traditions in Modern Italy, Princeton, NJ: Princeton University Press.

Putnam, R.D. (1995a), 'Bowling alone: America's declining social capital', Journal of Democracy, 6(1), 65-78.

Putnam, R.D. (1995b), 'Tuning in, tuning out: the strange disappearance of social capital in America', PS: Political Science and Politics, 28(4), 664-83.

Putnam, R.D. (1996), 'The strange disappearance of civic America', American Prospect, 24, $34-48$.

Putnam, R.D. (2000), Bowling Alone: The Collapse and Revival of American Community, New York: Simon \& Schuster.

Putnam, R.D. (ed.) (2002), Democracies in Flux: The Evolution of Social Capital in Contemporary Society, Oxford: Oxford University Press.

Putnam, R.D. (2004), 'Commentary: "Health by association": some comments', International Journal of Epidemiology, 33(4), 667-71.

Putnam, R.D. (2007), 'E pluribus unum: diversity and community in the twenty-first century - the 2006 Johan Skytte Prize Lecture', Scandinavian Political Studies, 33(2), 137-74. 


\section{Handbook of research methods and applications in social capital}

Putnam, R.D. and D. Campbell (2010), American Grace: How Religion Divides and Unites Us, New York: Simon \& Schuster.

Regnerus, M., C. Smith and D. Sikkink (1999), 'Who gives to the poor? The influence of religious tradition and political location on the personal generosity of Americans toward the poor', Journal for the Scientific Study of Religion, 37(3), 481-93.

Tocqueville, A. (1835 [1965]), Democracy in America, ed. J.P. Mayer, trans. George Lawrence, Garden City, NY: Doubleday.

Uslaner, E.M. (2008a), 'Where you stand depends upon where your grandparents sat: the inheritability of generalized trust', Public Opinion Quarterly, 72(4), 725-40.

Uslaner, E.M. (2008b), 'Trust as a moral value', in D. Castiglione, J.W. van Deth and G. Wolleb (eds), The Handbook of Social Capital, New York: Oxford University Press, pp. 101-21.

Warhurst, C. and D. Nickson (2001), Looking Good, Sounding Right? Style Counselling in the New Economy, London: The Industrial Society.

Woolcock, M. (2001), 'The place of social capital in understanding social and economic outcomes', Canadian Journal of Policy Research, 2(1), 11-17. 